\title{
Effect of Combined Use of Oral Prednisolone and Propranolol in the Treatment of Infantile Hemangioma: A Single Center Study
}

Tahmina Akhter Chowdhury ${ }^{1 *}$

Md. Saiful Hoque ${ }^{2}$

Roksana Hoque ${ }^{3}$

Alok Nandy ${ }^{4}$

'Department of Pediatric Surgery

Chattogram Medical College

Chattogram, Bangladesh.

${ }^{2}$ Department of Surgery

Chattogram Medical College

Chattogram, Bangladesh.

${ }^{3}$ Department of Dermatology and Venerology Chattogram Medical College

Chattogram, Bangladesh.

${ }^{4}$ Department of Anaesthesiology

Chattogram Maa-O-Shishu Hospital Medical College Chattogram, Bangladesh.

*Correspondence to:

Dr. Tahmina Akhter Chowdhury

Assistant Professor

Department of Pediatric Surgery

Chattogram Medical College Hospital

Chottagram, Bangladesh.

Mobile : +88 01733155155

Email:drpanna35cmc@gmail.com

Date of Submission ： 25.05 .2019

Date of Acceptance $\quad$ : 30.06 .2019

www.banglajol.info/index.php/CMOSHMCJ

\begin{abstract}
Background : Infantile hemangioma is a benign vascular tumor. Considerable controversy exists as to the management of hemangiomas. The purpose of this study was to see the efficacy and safety of orally administered prednisolone and propranolol in combination for treatment of potentially disfiguring or functionally threatening hemangiomas .
\end{abstract}

Materials and methods: In this prospective study, thirty two patients of hemangioma with age range of 1 month to 5 years were included who were treated with oral propranolol (1 $\mathrm{mg} / \mathrm{kg} /$ day in two divided doses) and oral prednisolone (2 $\mathrm{mg} / \mathrm{Kg} /$ day in single dose) in combination. This study was conducted in outpatient Department of Pediatric Surgery of Chattogram Medical College Hospital from January 2016 to December 2017. Changes in size and color of lesions were the two evaluating factors to see the efficacy of the treatment. Therapeutic response was graded as excellent, good, poor and no response.

Results: Overall therapeutic response was 92.62\% (29 patients). Excellent response was noted in 21 patients (65.62\%) and in 3 patients (9.38\%) there was no response. Range of treatment period was 6 to 20 weeks. No side effects except excessive weight gain was noted (6.25\%).

Conclusion: Combined use of low dose oral prednisolone and propranolol is more effective and safe for treatment of hemangioma.

Key words: Hemangioma; Prednisolone; Propranolol.

\section{INTRODUCTION}

Hemangioma or more appropiately Infantile Hemangioma (IH) is defined as benign neoplasm composed of proliferative and hyperplastic vascular endothelium. Although most of these tumors are small and innocuous, some may be life or function-threatening or have associated structural congenital anomalies ${ }^{1}$. They generally become evident within first few days of life and are characterized by an initial phase of rapid endothelial cell proliferation during the first year of life followed by a phase of slow involution ${ }^{2}$.

Medical therapies have become the mainstay in the management of IHs. Since 1970, oral steroids have been the standard therapy worldwide for serious or life-threatening IH cases. Oral Prednisolone or prednisone was commonly used as systemic steroid. Prednisolone accelerates the involution of IHs through differentiation and inhibition of angiogenesis. But only one third patient responds to systemic steroid ${ }^{3}$. Moreover these patients are at increased risk for infection, peptic ulceration, poor wound healing, stunted growth, and behavioral changes (Crying, insomnia, irritability). Several authors have reported successful management of IH by systemic steroid, with potentially serious side effects ${ }^{4,5}$. 
For last one decade, propranolol is being used for treatment of IHs. Its safety profile is well established when given to appropriate patients ${ }^{6}$. Though it is associated with some adverse effects such as hypotension, bradycardia, hypoglycemia and bronchospasm $^{7,8}$.

For treatment of problematic $\mathrm{IH}$, oral prednisolone and propranolol have shown excellent results individually. However, the combination of the two drugs in lower doses may also be used for the treatment of IH to avoid the complications associated with high doses of both drugs. One such study showed 95\% results when treated with prednisolone and propranolol in combination ${ }^{9}$. This combination treatment for IH is also cost effective and safe.

In this regard few studies are available internationally. In Bangladesh evidence based studies on the efficacy of newer modalities of treatment is still lacking. In Chattogram Medical College Hospital we started this combination therapy (Combination of low dose oral Prednisolone with low dose oral Propranolol) for treatment of IH from 2016. But no systematic study was done yet to see the overall outcome.

Therefore, this study will help us making local policies for patients and help us in reducing the morbidity. Keeping these facts in mind this study was conducted to find out an effective modality of treatment with minimum side effects for treatment of IH .

\section{MATERIALS AND METHODS}

This prospective observational study was conducted in the outpatient Department of Pediatric Surgery of Chattogram Medical College Hospital from January 2016 to December 2017. The patients of IH of both sexes with age ranging from 1 month to 5 years were included. For measurement facilities only superficial IHs was included. Changes in size and color of lesion were the two evaluating factors to see the efficacy of the treatment. Therapeutic response was graded as excellent, good, poor and no response. Patients having other systemic disease, previously treated, incomplete follow up and hemangiomas involving internal organs were excluded. Patients who have multiple IHs were also excluded from this study to simplify the outcome expectations.

Diagnosis was confirmed by consultant Pediatric Surgeon and / or consultant Dermatologist clinically and by Color Doppler ultrasound in some cases. Approval from the hospital Ethical Committee was taken. Written informed consent was taken from the parents/guardians of the patients after discussing the risks and benefits of the drugs. All the patients received treatment with oral prednisolone in a dose of $2 \mathrm{mg} / \mathrm{kg} /$ day in morning and propranolol in a dose of $1 \mathrm{mg} / \mathrm{kg} /$ day twice a day. The follow up of the patients were performed one week after initiation of treatment, then every four weekly till completion of treatment. Heart rate, random blood sugar and treatment compliance was checked during each visit along with outcome parameter. The response to the treatment was analyzed by grading scale of Table-I, which was used by Gangopadhyay et al and Chowdhury et al. ${ }^{10,11}$. In each visit the lesion was measured
(Length $\mathrm{x}$ breath) and its color change was marked to evaluate the response of IH to treatment. At every follow up photograph of the lesion was taken and it was compared to previous photographs.

Parameters used for grading the responses of IH to treatment

Excellent-Near total disappearance (More than $75 \%$ of pretreatment size) and color change from pretreatment state to color of surrounding normal skin (or near to normal skin color) of the patient.

Good-50\% to $75 \%$ regression in size with color change from pretreatment state to grey and sandy brown (Any one or in combination).

Poor- $25 \%$ to $50 \%$ regression in size with color change from pretreatment state to dull purple and pink bow (Any one or in combination).

In all patients treatment was continued for at least five weeks. If there was no regression in size and color after five weeks it was regarded as non responder. In case of responder, treatment continued till response of IH to combine therapy persisted.

\section{RESULTS}

Thirty two patients of IH who fulfilled the inclusion/exclusion criteria were enrolled to determine the outcome of treatment by combination of low dose oral Prednisolone with oral Propranolol. Patient's demography is shown in Table I.

Table I : Demography of patients

$\begin{array}{lrr}\text { Total patients (n) } & 32 & \\ \text { Neonate (day 1 - day 28) } & 2 & (6.25 \%) \\ \text { Infant ( } 2^{\text {nd }} \text { month t- } 1 \text { year) } & 19 & (59.37 \%) \\ \text { Children (2nd year }-5 \text { year) } & 11 & (34.38 \%) \\ \text { Male } & 7 & \\ \text { Female } & 25 & \\ \text { Male : Female } & 1: 3.57\end{array}$

Duration of treatment ranges from six weeks to twenty weeks. Distribution of $\mathrm{IH}$ according to anatomical site is shown in Table II. Among the 32 patients, 29 (90.62\%) patients responded to combined therapy of prednisolone and propranolol. Only three patients $(9.38 \%)$ did not respond at all. All these three patients were children (3yr 7 months, 4 yr 3months \& 4 yr 9 months). Pattern of response of hemangioma to combined therapy of propranolol and prednisolone is shown in table III.

Table II : Distribution of IH according to anatomical site

\begin{tabular}{llrr} 
Anatomical site & $(\mathbf{n}=\mathbf{3 2})$ & No. of patients & $(\mathbf{\%})$ \\
Head \& Neck & Segmental & 5 & $(56.24)$ \\
& Single & 13 & \\
Upper limb & & 3 & $(9.38)$ \\
Trunk & & 6 & $(18.75)$ \\
Lower limb & & 2 & $(6.25)$ \\
Perineum & & 3 & $(9.38)$ \\
\hline
\end{tabular}


Table III : Pattern of response of hemangioma to combined therapy.

\begin{tabular}{lrrrr} 
Grading of response & \multicolumn{2}{c}{$\begin{array}{c}\text { No of patient according to age } \\
\text { Neonate }\end{array}$} & $\begin{array}{r}\text { Total No. of } \\
\text { Infant }\end{array}$ & $\begin{array}{r}\text { Children } \\
\text { patient (\%) }\end{array}$ \\
Excellent & 2 & 15 & 4 & $21(65.62)$ \\
Good & 0 & 4 & 2 & $6(18.75)$ \\
Poor & 0 & 0 & 2 & $2(6.25)$ \\
Total no. of responded patient & & & 29 & $(90.62)$ \\
No response & 0 & 0 & 3 & $3(9.38)$ \\
\hline
\end{tabular}

Recorded side effects were excessive weight gain in two patients $(6.25 \%)$. In seven patients there was gastrointestinal upset which was improved with conservative treatment.There was no change in blood pressure and heart rate of the patients after starting treatment and in follow up visits.

\section{DISCUSSION}

$\mathrm{IH}$ is one of the most misdiagnosed and maltreated clinical problems in Bangladesh. In this study, we found that female patients were more in number and male to female ratio was 1:3.57. Infant was the common age group of our study. These two findings are similar to other studies ${ }^{11,12,13}$.

With single use of prednisolone treatment time varies from 1224 weeks and with single use of propranolol, average duration of treatment is 24 weeks ${ }^{14}$. While duration of treatment was six to twenty weeks in our study.

We found head \& neck region as the commonest (56.25\%) site of hemangioma like some other studies ${ }^{1,4,11}$.

In our study, overall response rate was $90.62 \%$ and excellent response was recorded in $65.62 \%$ patients; good and poor response was noted in $18.75 \% \& 6.25 \%$ patient respectively. Only $9.38 \%$ patients showed no response to treatment though there was no further proliferation of IH in the non responder group. There were two neonates in this study and in both of them IH regressed completely with no residual fibro-fatty tissue. Anzum et al showed excellent response in $56.16 \%$ patients, good in $23.29 \%$, moderate in $15.07 \%$, slight improve- ment in $4.11 \%$ and $1.37 \%$ patients showed no response ${ }^{13}$. With single use of prednisolone and propranolol excellent response rate were $9.61 \%$ and $80.76 \%$ respectively in another Bangladeshi studies though in that study excellent response was denoted as $80 \%$ regression in size of hemangioma lesion ${ }^{12}$.

We found side effects only in two patients and it was excessive weight gain (According to WHO growth chart). But high dose prednisolone $(5 \mathrm{mg} / \mathrm{kg} /$ day or more) which was used for treatment of problematic IH has many potential side effects like hypertension and cushinoid facies ${ }^{5,14}$. Some studies showed that propranolol had caused hypoglycemia, bradycardia and hypotension when used in normal dose (2-3 mg/kg/day) for treatment of hemangioma ${ }^{12,15,16}$. In seven patients there was gastrointestinal upset and all of them improved with conservative management. None of them needed hospital admission and $i / v$ fluid. Though prednisolone might cause gut irritation but it could not be differentiated whether this GI upset was prednisolone induced or not.

\section{CONCLUSION}

The authors concluded that regression rate is higher if low dose oral prednisolone with oral propranolol is used for treatment of infantile hemangioma. The study also showed that potential side effects of prednisolone and propranolol can be reduced or avoided if both the drug is used in low dose and in combination.

\section{ACKNOWLEDGEMENT}

The authors gratefully acknowledge the support of all doctors and staffs of department of Pediatric surgery $\mathrm{CMCH}$. The authors also appreciating the kind contributions of their colleagues of Department of Dermatology and Venerology $\mathrm{CMCH}$.

\section{DISCLOSURE}

All the authors declared no competing interests. 


\section{REFERENCES}

1. Smithers CJ, Fishman SJ. Vascular Anomalies . In: Holcomb G.W. III, Murphy J.P. Editors. Ashcraft’s Pediatric Surgery, $5^{\text {th }}$ ed. Philadelphia: Saunders Elsevier. 2010; 982-985.

2. Chang LC, Haggstrom AN, Drolet BA, Baselga E, Chamlin SL, Garzon MC. Growth characteristics of infantile hemangiomas: Implications for management. Pediatrics. 2008;122:360-367.

3. Bennett ML, Fleischer AB, Chamlin SL, Frieden IJ. Oral corticosteroid use is effective for cutaneous hemangiomas: An evidence-based evaluation. Arch Dermatol. 2001;137:1208-1213.

4. Klement G Fishman SJ. Vascular Anomalies :Hemangioma and Malformations. In :Grosfeld JL,O'Neil JA Jr. Fonkalsrud E.W, Coran A.G, editors. Pediatric Surgery, $6^{\text {th }}$ edn, Philadelphia, Mosby Elsevier. 2006; 2094-2106.

5. Nieuwenhuis K, Laat PCJ, Janmohamed SR, Madern GC, Oranje AP. Infantile Hemangioma :Treatment with Short Course Systemic Corticosteroid Therapy as an Alternative for Propanolol. Journal of Pediatric Dermatology. 2013; 30(1): 64-70.

6. Chik KK, Luk CK, Chan HB, Tan HY. Use of propranolol in infantile hemangioma Chinese children. Hoong Kong Med J. 2010;16:341-346.

7. Sans V, Dumas de la RE, Berge J, Grenier N, Boralevi F, Mazereeuw-Hautier et al. Propranolol for severe infantile hemangiomas: follow-up report. Pediatrics. 2009;124:423-431.

8. $\quad$ Lawley LP, Siegfried E, Todd JL. Propranolol treatment for hemangioma of infancy: Risks and recommendations. Pediatr Dermatol. 2009;26:610-614.

9. Koaya ACA, Choo MM, Nathan AM, Omar A, Lim CT. Combined low dose oral propranolol and Oral Prednisolone as First-Line Treatment in Periocular Infantile Hemangiomas. J Ocular Pharmacology and Therapeutics. 2011;27:309-311.

10. Gangopadhyay AN, Sharma SP, Gopal SC, Gupta DK, Panjawani K, Sinha JK. Local steroid therapy in cutaneous hemangioma, Indian Pediatrics. 1996;33:31-33.

11. Chowdhury TA, Hoque MS. Inlesional Dexamethasone in treatment of Hemangioma: Analysis of Outcome. J Pediatr NeonatalCare 5(4): 00191.DOI:10.15406/JPNC.2016.05.00191.

12. Hoque MM, Ferdous KMN, Saha BK, Paul SK, Islam MK. Oral Propranolol and Prednisolone in the Treatment of Infantile Hemangioma: A Comparative Study. Chattogram Maa-O-Sishu Hospital Medical College Journal. 2014;13(1):26-31.

13. Anjum MZ, Pasha KHK, Abbas SH, Zubair M. The outcome of combination of low dose oral prednisolone with propranolol for the treatment of infantile hemangioma:Pak J Med Sci. 2016;32(1):211-214.

14. Khan AR. What is new in the Management of Hemangioma, Power point presentation in the $1^{\text {st }}$ global congress for consensus in Pediatrics and child Health. 2011.

15. Sans V, Dumas de la RE, Berge J, Grenier N, Boralevi F, Mazereeuw-Hautier J et al. Propranolol for severe infantile hemangiomas: followup report. Pediatrics. Epub. 2009;124 (3): e423-431.

16. Lawly LP, Siegfried E,Todd JL. Propranolol treatment for hemangioma of infancy : Pediatr Dermatol. 2009;26(5): 610-614. 